\title{
Investigation of steel to dielectric transition using microminiature eddy-current converter
}

\author{
Vladimir Malikov ${ }^{1, *}$, Sergey Dmitriev ${ }^{1}$, Alexey Ishkov $^{2}$, Alexander Katasonov ${ }^{1}$, and Anatoly \\ Sagalakov ${ }^{1}$ \\ ${ }^{1}$ Altai State University, 634049 Barnaul, Russia \\ ${ }^{2}$ Altai State Agricultural University, 634049 Barnaul, Russia
}

\begin{abstract}
The research aims to develop a microminiature converter for electrical steel investigation. The research topic is considered relevant due to the need for evaluation and forecasting of safe operating life of electric steel products. The authors determined the capability to study steel characteristics at different depths based on variations of eddy-current converter amplitude at the steel-dielectric boundary. A microminiature transformer-type converter was designed, which enables to perform local investigations of ferromagnetic materials using eddy-current method based on local studies of the steel electrical conductivity. Having the designed converter as a basis, a hardware-software complex was built to perform experimental studies of steel at the interface boundary. A system was developed for automated converter relocation above the studied object at a specified velocity. Test results are reported for a specimen with continuous and discrete measurements taken at different frequencies. Response dependence of eddy-current converter was found to demonstrate non-linear behavior at steel to dielectric transition. The effect of gap between the eddy-current converter and the test object is investigated.
\end{abstract}

\section{Introduction}

Today, the issue of accurate and reliable evaluation of technical condition of hazardous production facilities has special importance. In modern control methods such evaluation is mainly based on probabilistic approaches and is performed using actual data on operation modes and existing stresses, deformations and temperatures. While structure and surface changes taking place in metals are almost neglected [1,2]. However, it is known [3] that when stressed metal experiences changes not only in volume, but on its surface. In this regard, it should be reasonable to evaluate changes occurring in metals using methods and devices that allow tracking properties of the surface.

Electric steel is applied for manufacturing various electrical products. Magnetic properties of steel are essential for developing effective control and diagnostic methods for their physical and chemical characteristics which largely define reliability, operating life and remaining useful life of critical joints, components, products in various industries. The works [4-6] demonstrate successful use of hysteretic loop parameters, as well as magnetic

*Corresponding author: osys11@gmail.com 
and magnetoacoustic noises for control of physical and chemical properties of ferromagnetic steels.

Eddy-current method is also proved [7, 8] effective for investigation on physicomechanical properties of steel. This method is a widely used means of non-destructive testing based on analyzing interaction between external electromagnetic field and eddy currents induced by this field.

The works [9-11] suggest the method for brittle fracture evaluation in metal equipment made of 09Г $2 \mathrm{C}$ low-alloy steel by means of electromagnetic control method with the use of transmission gages and attachable gages.

The eddy-current control method is often used for evaluation of various steel parameters. The investigations $[12,13]$ demonstrated practicality of using such method for fault location in AISI 304 steels. At the same time, the developed gage positioning system with the pitch of $0.1 \mathrm{~mm}$ was used for accurate gage movement. The work [14] highlights that one of the obvious advantages of using eddy-current method for investigation of conductive materials is its applicability for diagnostic of materials with paint and varnish, and other non-conductive coatings.

The purpose of this study is to demonstrate the ability to scan steel to dielectric transition for further investigation of steel surface characteristics. In this regard, it is necessary to define the mode of decrease of induced voltage of eddy-current converter when distancing from the test object, and the cause of such decrease. Another relevant parameter is the mode of induced voltage increase in the converter when approaching the test object. Presentation of induced voltage changes in the form of mathematical dependences enables to elicit the ways of interaction between electromagnetic field of eddy-current converter and residual magnetic field of steel.

The research is aimed at development, investigation, optimization and testing of microminiature eddy-current converter for steel analysis. An important task within the research is to obtain dependences describing the range of response of the eddy-current converter to the change of its parameters and physico-mechanical properties of the studied steels.

\section{Materials and Methods}

A unit based on eddy-current converter (ECC) [15-18] and a digital displacement transducer (DDT) were used for measuring stress-strain behavior on the boundary of dielectric and conductive ferromagnetic space.

Eddy-current converter represents a transformer with measuring, transmitting and compensation coils and a coil flux guide located inside a cylindrical platform. Grooves are arranged on the external side of the platform to locate the coils impregnated with compound at the temperature of $200 \mathrm{Co}$. This prevents destruction when applying ferrite screen meant for localization of electromagnetic field on the test object. On the exterior, ECC is put into alumina bead which protects the core from contacting with the test object.

Parameters of the designed ECC allow effectively localizing magnetic field within the area of $2500 \mathrm{mkm}^{2}$ and provide its considerable penetration deep into the test object when operating at low frequencies [16].

Measurement system is based on a sine-wave voltage generator. The voltage is transmitted to the transmitting coils of the ECC and generates electromagnetic field which penetrates into the test object and induces eddy currents in it. Eddy currents induce voltage in the measuring coil, which carries information on the parameters of the test object. The voltage is settled and cleared using selective amplification system with a glitch filter.

After filtration the signal is transmitted to envelope detector and then to the PC through an analog-to-digital converter (ADC). Frequency of the generated signal and cut-off 
frequency of filtration system change simultaneously. This makes possible to distinguish the useful signal that carries information on the test object parameters. Programmed control enables to vary operating frequency of the measuring system.

Experimental study was performed using two materials located with $1 \mathrm{~cm}$ gap between each other. Scanning measurements were initially taken in electric steel of type 1212 (specimen No.1) through a dielectric (paper), and then in steel of type 3414 (specimen No.2). Frequency of signal transmitted to the transmitting coil of the ECC varied within the range of 1000-10000 Hz. The measurable parameter was voltage induced in the measuring coil of the ECC in the process of its displacement from the initial scanning point. The converter displacement was measured using a digital displacement transducer (DDT). The data were digitalized with the help of an ADC and then in real-time mode were transmitted to the software that controls the measuring system. Origin math tool was used for data analysis.

The induced voltage was measured both continuously by moving the EDD with the constant velocity of $1 \mathrm{~mm} / \mathrm{s}$, and discretely by moving the EDD with the pitch of $0.1 \mathrm{~mm}$ and time of $0.5 \mathrm{~s}$ for each pitch. The described measurement method is determined by characteristics of the developed hardware-software complex, such as ADC sampling frequency and DDT operating speed, and is proved effective for steel investigation [13].

\section{Experimental results}

For the purpose of detailed study of induced voltage on the ferromagnetic-dielectric boundary, a dependence curve of induced voltage amplitude on the gage position was obtained. This curve demonstrates the behavior of induced voltage amplitude variation while moving the ECC above the steel-dielectric boundary. The variations were observed starting from the point located $5 \mathrm{~mm}$ away from the edge of the first specimen up to the point corresponding to the distance of $5 \mathrm{~mm}$ from the edge of the second specimen. This way, one can observe ferromagnetic-dielectric interface which is qualitatively related to the distance up to and beyond the edge of the test object. The dependence curve of induced voltage amplitude on the gage position explicitly demonstrates the effects occurring on the interface. The experimental results are presented in Figure 1.

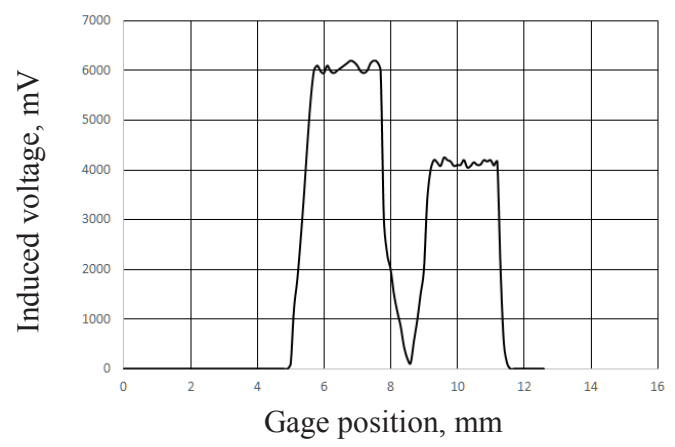

Fig. 1. Dependence curve of induced voltage on the gage position while continuous scanning at $1000 \mathrm{~Hz}$.

Difference of peaks of the curves depends on the permeability of electric steel. The curve demonstrates that in the dielectric area the induced voltage drops from $6000 \mathrm{mV}$ to $2000 \mathrm{mV}$ and then smoothly tends to zero. For more detailed study of induced voltage drop on the ferromagnetic-dielectric boundary, a curve for discrete dependence of induced voltage amplitude on the gage position was obtained (Fig. 2). Discrete scanning of objects 
was planned within the experiment. Measurements were performed in points located at $0.1 \mathrm{~mm}$ from each other.

As a result of the experiment the following conclusion can be drawn: on the interface, ferromagnetic response does not drop to zero value, but decreases according to square law (area 1). The minimum value of induced voltage amplitude is $50 \mathrm{mV}$. Increase of the signal amplitude when approaching the second steel specimen occurs according to a law similar to exponential one (area 2).

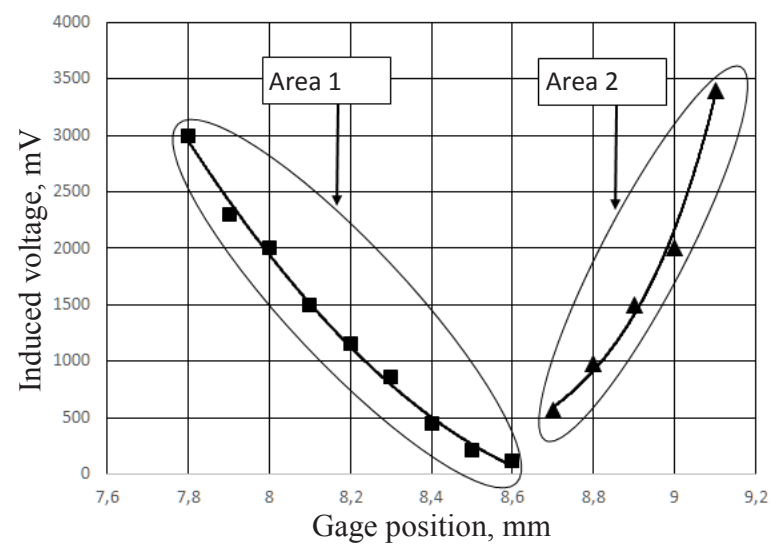

Fig. 2. Dependence curve of induced voltage amplitude on the gage position while discrete scanning at $1000 \mathrm{~Hz}$.

Such dependence can be explained by residual voltage in coils of ECC. Continuous field lines are distinguished in the field of electric steel. Therefore, electromagnetic field that prevents occurrence of self-inductance in the measuring coil and is generated by eddy currents will have little effect on induced voltage. At the same time, the response value will not drop to zero due to ferromagnetic influence on the gage.

Such influence is explained by presence of self-magnetic field of steel which is closed on the ECC even at relatively big distance. In this case, the value of induced voltage is considerably lower than the value of voltage induced in the converter when positioning the gage right above the steel specimen. This voltage keeps reducing with the increase of distance between the gage and the test object.

When approaching the second specimen, induced voltage amplitude increases. In such case, magnetic fields of the first and the second specimens affect the gage simultaneously. Exponential growth of induced voltage amplitude is caused by adding electromotive forces (EMF) of both specimens' fields.

Another experiment was performed to assess the effect of ECC signal frequency on measurement results. The dependence curve of induced voltage amplitude on the gage position was obtained, which demonstrated variation of the amplitude when moving the gage at the frequency of $10000 \mathrm{~Hz}$. The experimental results are presented in Figure 3. 


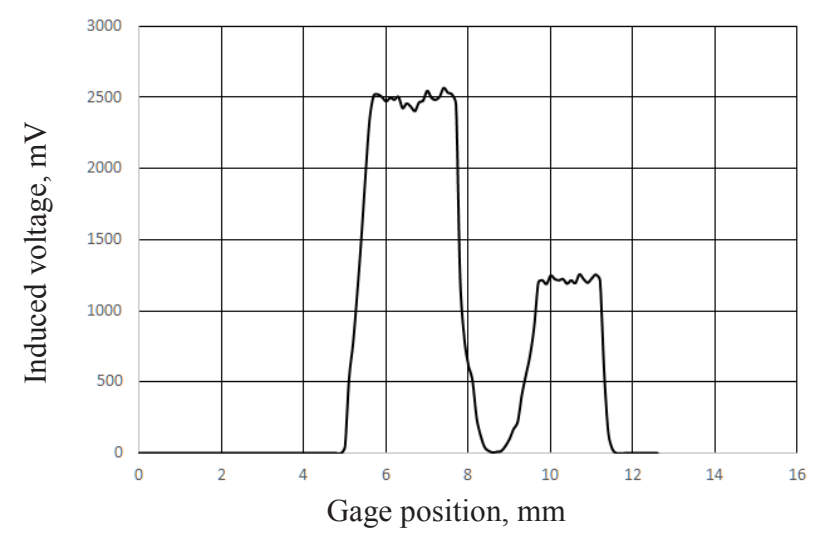

Fig. 3. Dependence curve of ECC induced voltage on the gage position while continuous scanning at $10000 \mathrm{~Hz}$.

The curve shows that the gage position has almost no effect on qualitative dependence of ECC induced voltage. The two peaks of induced voltage correspond to two types of studied steel. Drop of induced voltage is caused by dielectric which separates the two specimens. One can well notice the varied rate of induced voltage drop and the minimum value of induced voltage $(5 \mathrm{mV})$ which corresponds to the moment when the gage comes through the dielectric. Such dependence can be explained by increased magnetic loss in steel with the increase of current frequency in the ECC up to $10000 \mathrm{~Hz}$.

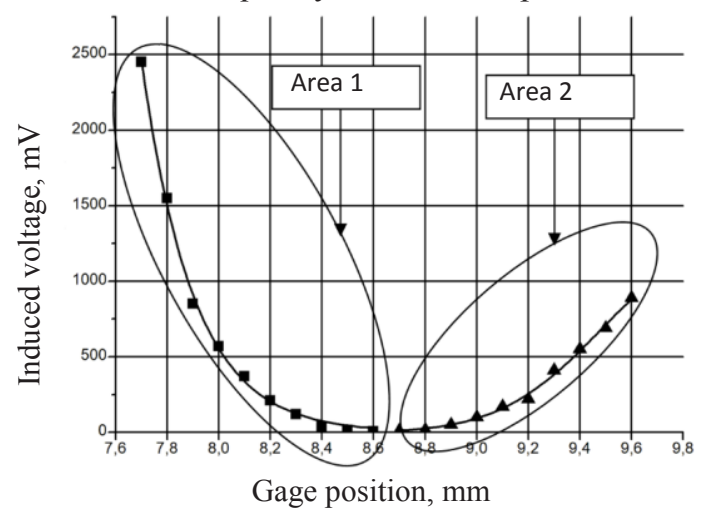

Fig. 4. Dependence curve of induced voltage on the gage position while discrete scanning at $10000 \mathrm{~Hz}$.

Magnetic field of specimens at such frequency has considerably smaller effect on induced voltage compared to that corresponding to $1000 \mathrm{~Hz}$. Figure 4 shows that induced voltage drop in area 1 occurs according to exponential law $=a e^{b x}$. Increase of induced voltage in area 2 also leads to exponential law $y=e^{a+b x+c x^{2}}$.

During the final experiment the influence of gap between ECC and electric steel on induced voltage was studied. Within the experiment discrete scanning of specimen No.1 was performed. The gap grows with the pitch of $0.1 \mathrm{~mm}$, measurements were taken at the frequency of $1000 \mathrm{~Hz}$. The experimental results are presented in Figure 5. 


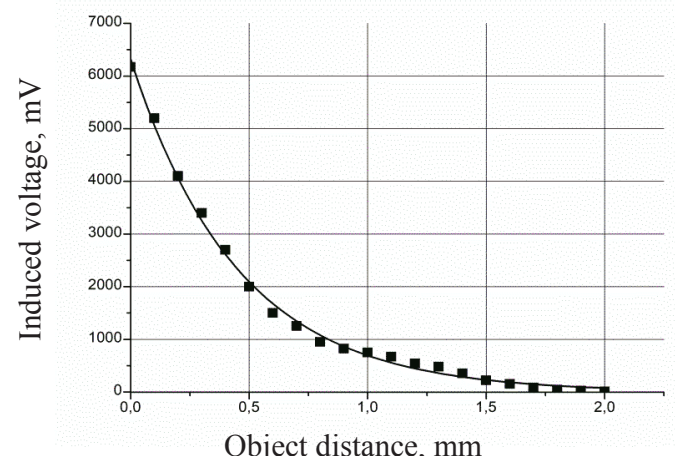

Fig. 5. Dependence curve of induced voltage on gap while discrete scanning at $1000 \mathrm{~Hz}$.

The curve demonstrates that when increasing the distance between the gage and the test object induced voltage decreases according to exponential law. This can be justified by the fact that penetration depth of electromagnetic field in transmitting coil is insufficient for generating counterfield in ferromagnetic which will be strong enough to generate induced voltage in measuring coil of the converter. Besides, the effect of magnetic lines on coils of the ECC becomes weaker as the distance grows.

\section{Conclusion}

As a result of the research, a measurement system for electric steel parameters is developed. The investigation revealed practicability of scanning steel to dielectric transition using eddy-current converter. Obtained measurement data allowed describing interaction between magnetic field of ECC and residual magnetic field of steel.

In addition, mathematical functions were obtained to describe variation of induced voltage while scanning similar transitions at various ECC signal frequencies. Changing ECC signal frequency enables to investigate test objects at various depths, but it is required to establish unique dependence between the ECC response and the penetration depth of ECC magnetic field into various types of steel. Moreover, mathematical functions were obtained to describe variation of induced voltage with varied gap, which allows using the developed system for scanning objects with paint and varnish, and other non-conductive coatings.

Based on the conducted research a certain conclusion can be made on the state of the studied object with regard to behavior of ECC induced voltage variation. The investigation also proves that the measurement system is appropriate for thickness measurement and for studying structural properties of steel. Further extension of the method will allow assessing quality of studied material by its comparison with check specimens of corresponding types of steel.

The presented eddy-current converter for structural materials investigation can be used for diagnostic and control of critical joints and structural machine elements used in electrical engineering.

\section{References}

1. I.R. Kuzeev, Jelektromagnitnaja diagnostika oborudovanija neftehimicheskih $i$ neftepererabatyvajushih proizvodstv [Electromagnetic diagnostics of equipment at petrochemical and oil refining enterprises] (UGNTU, Ufa, 2001) (in Russian) 
2. O.G. Kondrashova, Opredelenie resursa bezopasnoj jekspluatacii neftegazovogo oborudovanija putem ocenki adaptivnyh svojstv metalla po izmeneniju ego magnitnyh harakteristi [Determination of safe operating life of oil and gas equipment by estimating the adaptive properties of metal on changing its magnetic characteristics], $\mathrm{PhD}$ thesis (Ufa, 2006) (in Russian)

3. V.S. Ivanova, Razrushenie metallov [Fracture of Metals] (Metallurgiya, Moscow, 1979) (in Russian)

4. V.V. Kluyev, Nerazrushajushhij kontrol' [Non-Destructive Testing] (Mashinostroenie, Moscow, 2004) (in Russian)

5. V.V. Filinov, V.E. Shaternikov, P.G. Arakelov, Russ. J. Nondestruct. 50(12), 58 (2014)

6. V.V. Filinov, V.E. Shaternikov, Russ. J. Nondestruct. 50(10), 47 (2014)

7. N.M. Rodigin, I.E. Korobeynikova, Kontrol' kachestva izdelij metodom vihrevyh tokov [Eddy-current testing of products quality] (Mashgiz, Moscow, 1958) (in Russian)

8. V.V. Kluyev, Pribory dlja nerazrushajushhego kontrolja materialov i izdelij [Devices for non-destructive testing of materials and products] (Mashinostroenie, Moscow, 1976) (in Russian)

9. R. Ghoni, M. Dollah, A. Sulaiman, F.M. Ibrahim, Advances in Mechanical Engineering 6, 1 (2015)

10. E.M. Bashirova, Ocenka predel'nogo sostojanija metalla oborudovanija dlja pererabotki uglevodorodnogo syr'ja s primeneniem jelektromagnitnogo metoda kontrolja [Using electromagnetic inspection method for evaluation the extreme limit state of the metal of equipment for processing hydrocarbon raw materials] (Ufa, 2005) (in Russian)

11. T.R. Bikbulatov, E.A. Naumkin, V.A. Petrov, Himicheskaja tehnika [Chemical Equipment] 3, 11 (2010) (in Russian)

12. J.M. Szlagowska-Spychalska, M.M. Spychalski, K.J. Kurzydlowski, NDT and E International 54, 56 (2013)

13. G. Almeida, J. Gonzalez, L. Rosado, P. Vilaça, T.G. Santos, Procedia CIRP 7, 359 (2013)

14. D. Rifai, A.N. Abdalla, ARPN J. Eng. Appl. Sci. 11, 1 (2015)

15. S.F. Dmitriev, A.O. Katasonov, V.N. Malikov, A.M. Sagalakov, Russ. Eng. Res. 36(8), 626 (2016)

16. V.N. Malikov, S.F. Dmitriev, M.A. Davydchenko, A.M. Sagalakov, A.V. Ishkov, AIP Conf. Proc. 1785, 030014 (2016)

17. V.N. Malikov, S.F. Dmitriev, A.M. Sagalakov, A.O. Katasonov, Russ. J. Nondestruct. 52(1), 32 (2016)

18. S.F. Dmitriev, V.N. Malikov, A.M. Sagalakov, L.I. Shevtsova, Welding International 31(8), 608 (2017) 